\title{
Quality of Life in Chronic Hemodialysis Patients
}

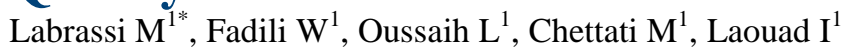

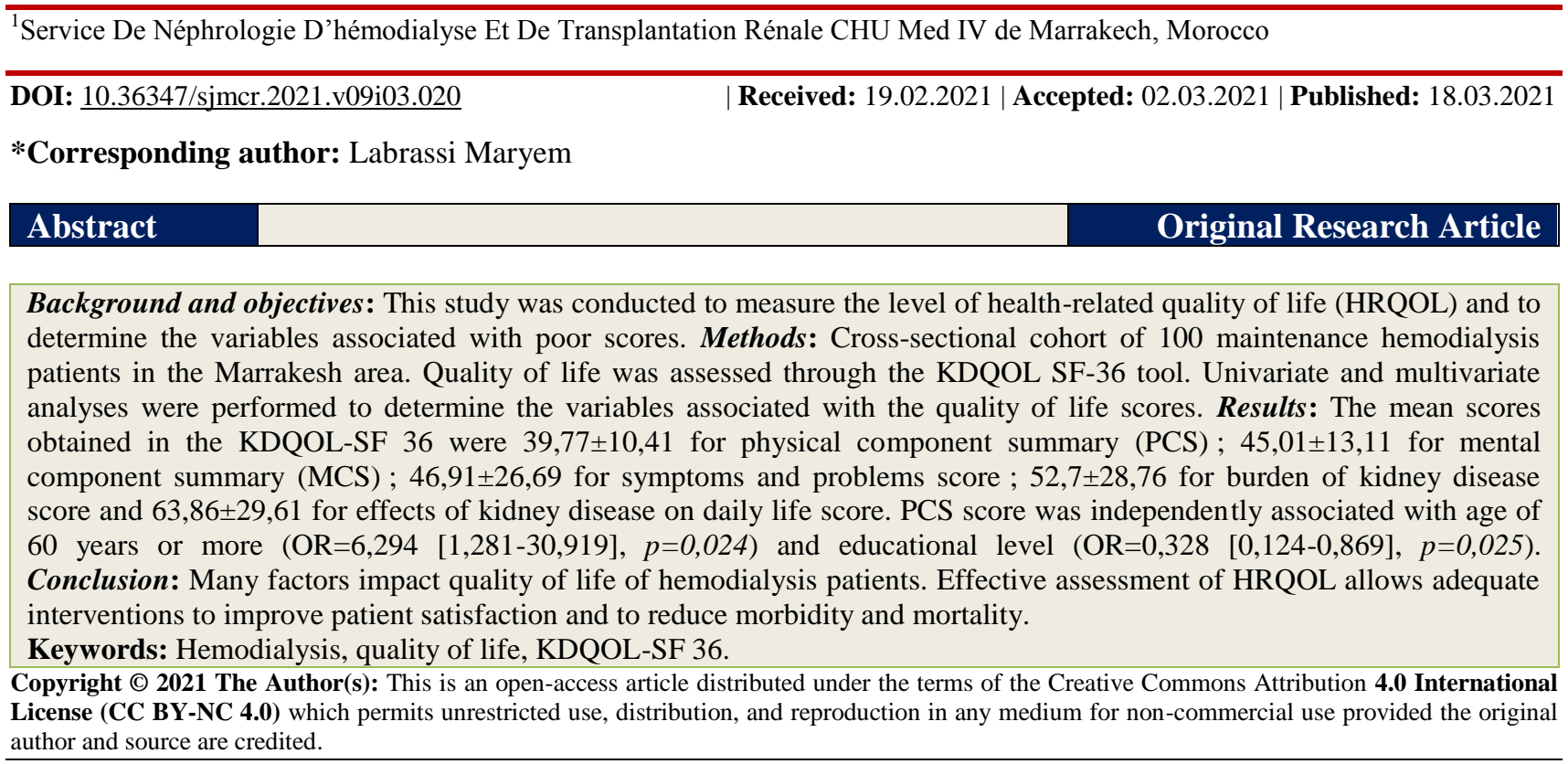

\section{INTRODUCTION}

Alteration of health-related quality of life (HRQOL) in patients under dialysis is well known [1].

As more and more people are requiring renal replacement therapy, a multidimensional approach is necessary to assess both the functional status of the patients and the perception of their own health. HRQOL represents the physical, psychological and social domains of health that are influenced by a person's experience, beliefs, expectations and perceptions [2].

Physical, mental and social well-being are important components of therapeutic management of dialysis patients due to the number and complexity of stressors faced by these patients.

It is therefore important to assess the impact of interventions by measuring HRQOL in order to improve patient satisfaction and outcome [3].

This global concept of health encouraged the use of HRQOL tools. Optimal HRQOL measurement instruments evaluate all aspects of the impact of the disease and its treatment on the physical, emotional, social and mental dimensions of an individual [4].

Multiple different instruments have been developped, most of them use a psychometric approach which is based on the item measure theory [5].
The Kidney Disease Quality of Life (KDQOL) instrument was designed for use in hemodialysis patients. It uses the Medical Outcomes Study Short- Form 36 (also abbreviated as SF-36) as its core and represents a reliable and valid global generic assessment tool in hemodialysis patients.

The purpose of our study is to evaluate HRQOL in chronic hemodialysis patients based on a Moroccan translated version of KDQOL-SF36 [6].

\section{Patients \& Methods Population}

We conducted a multicenter cross-sectional study between March and May 2019, recruiting all adult patients aged more than 18 years and undrgoing hemodialysis for more than 3 months in two different urban dialysis centers in Marrakesh, Morocco.

Exclusion criteria were: inability to answer the questions, previous diagnosis of psychotic disorders, refusal to participate to the study and a recent history of hospitalization during the last 3 months.

We obtained demographic (age, gender, amount of education, profession, social conditions, tobacco use and drinking habits) and medical data (initial kidney disease, comorbid conditions, number of years of dialysis and number of hospitalizations during the last year). Dialysis parameters (dialysis dose, dry weight, interdialytic weight gain and vascular access) and biological parameters (serum levels of hemoglobin, C-reactive protein, albumin, protids, triglycerids, 
Labrassi M et al., Sch J Med Case Rep, Mar, 2021; 9(3): 269-273

cholesterol, parathyroid hormone (PTH), calcium, phosphorus and fasting blood glucose) were recorded at the moment of their inclusion in the study.

HRQOL was measured in all patients through a validated translation version of the KDQOL-SF 36 test in Moroccan dialect [6].

\section{Statistical Analysis}

Statistical analysis was performed using SPSS, version 22. Quantitative variables were reported as mean \pm SD or median (min-max), and quantitative variables as percentage. The level of significance was set at $p<0,05$. The KDQOL-SF 36 scores were calculated based on the recommendations and tables provided by the KDQOL Working Group [7]. Patients with scores closer to 100 in the KDQOL-SF 36 have higher levels of quality of life.

\section{RESULTS}

A total of 100 patients were screened for the study. The meanage of the participants was 49,71 $\pm 15,20$ years, and 53\% were male. Most patients had elementary (19\%) and secondary (15\%) education; $70 \%$ lived with their spouses and/or children, 54\% were no longer working; and 35\% benefited from healthcare for low-income while $63 \%$ had health insurance.

Demographic, clinical and laboratory characteristics of the patients are presented in Table-1.

The mean scores obtained in the KDQOL-SF 36 were $39,77 \pm 10,41$ for physical component summary (PCS) ; $45,01 \pm 13,11$ for mental component summary (MCS); $46,91 \pm 26,69$ for symptoms and problems score ; 52,7 $\pm 28,76$ for burden of kidney disease score and 63,86 $\pm 29,61$ for effects of kidney disease on daily life score. Table 2 shows the mean scores in each category (Table-2).

A PCS score of $<51$ was found in $59,6 \%$ of patients, a MCS score < 43 was found in $62,6 \%$ of patients and $38,4 \%$ of patients had both PCS and MCS scores under 51 and 43 respectively.

The scores were analyzed against age, sex, social conditions, education level, health care insurance, comorbidities (arterial hypertension, cardiovascular disease, diabetes mellitus, anemia and hyperparathyroidism), number of years of dialysis, dialysis dose and number of days of hospitalization.

The evaluation of KDQOL-SF 36 scale scores by demographic and clinical factors showed that there was no significant association of all quality of life dimensions with sex, marital status and the presence of diabetes and hypertension.

Patients aged 60 or more had poorer PCS score $(\mathrm{p}=0,001)$. Patients' educational level had a significant influence on PCS score $(\mathrm{p}=0,006)$ but not on MCS score. To be employed tended to be associated with better MCS score $(\mathrm{p}=0,05)$. Dialysis dose was positively associated with PCS score $(\mathrm{p}=0,002)$ and a PTH rate of more than $300 \mathrm{pg} / \mathrm{ml}$ was negatively associated with PCS score $(\mathrm{p}=0,023)$.

The presence of cardiovascular disease was significantly associated with worse score of symptoms/problems score $(\mathrm{p}=0,005)$ and MCS score $(\mathrm{p}=0,005)$.

In multivariate analysis, PCS score was independently associated with age of 60 years or more $(\mathrm{OR}=6,294[1,281-30,919], \mathrm{p}=0,024)$ and educational level $(\mathrm{OR}=0,328[0,124-0,869], \mathrm{p}=0,025)$.

Table-1: Characteristics of study subjects $(\mathrm{N}=100)$

\begin{tabular}{|c|c|}
\hline Characteristics & Value \\
\hline Age (mean value) years old & 49,71 \\
\hline Males (\%) & 53 \\
\hline Sex ratio & 0,9 \\
\hline Education level (\%) & \\
\hline Illiterate & 28 \\
\hline Elementary & 19 \\
\hline Middle school & 15 \\
\hline High school & 20 \\
\hline Graduate studies & 18 \\
\hline Employment status (\%) : & \\
\hline Unemployed & 54 \\
\hline Casual employment & 10 \\
\hline Official & 14 \\
\hline Liberal profession & 10 \\
\hline Retired & 12 \\
\hline Marital status (\%) : & \\
\hline Maried & 70 \\
\hline Causal nephropathy (\%) : & \\
\hline Glomerulonephritis & 12 \\
\hline Hypertensive nephropathy & 25 \\
\hline Interstitial nephropathy & 3 \\
\hline Uropathies & 3 \\
\hline Indetermined & 57 \\
\hline Comorbities (\%) : & \\
\hline Arterial hypertension & 73 \\
\hline Diabetes & 12 \\
\hline Cardiovascular disease & 19 \\
\hline Arteriopathies & 5 \\
\hline Stroke & 4 \\
\hline Neoplasia & 2 \\
\hline Autoimmune diseases & 3 \\
\hline Alcohol and drug addiction & 4 \\
\hline Dialysis parameters : & \\
\hline Dialysis duration (mean) years & 8,34 \\
\hline Dialysis dose (mean KT/V) & 1,39 \\
\hline $\mathrm{BMI}\left(\mathrm{Kg} / \mathrm{m}^{2}\right)$ & 23,62 \\
\hline Biological data (mean values): & \\
\hline Hemoglobin $(\mathrm{g} / \mathrm{dl})$ & 10,82 \\
\hline Parathormon level (pg/l) & 1143,29 \\
\hline Calcemia (mg/l) & 88,71 \\
\hline Phosphoremia (mg/l) & 52,14 \\
\hline Albuminemia (g/l) & 42,91 \\
\hline LDL-cholesterol (g/l) & 1,71 \\
\hline HDL-cholesterol (g/l) & 0,78 \\
\hline Triglycerids $(\mathrm{g} / \mathrm{l})$ & 1,64 \\
\hline
\end{tabular}


Labrassi M et al., Sch J Med Case Rep, Mar, 2021; 9(3): 269-273

Table-2: Mean KDQOL SF-36 QOL scores

\begin{tabular}{|c|c|}
\hline \multicolumn{2}{|l|}{$\begin{array}{l}\text { Parameters } \\
\text { General health }\end{array}$} \\
\hline General health & \\
\hline General health perceptions & 42,5 \\
\hline Health- related limitations of activities : & \\
\hline - Moderate activities & 68,5 \\
\hline - Climbing several flights of stairs & 68,68 \\
\hline Role limitations caused by physical problems : & \\
\hline - Incompletly accomplished work & 48 \\
\hline - Limited types of activities & 18 \\
\hline Role limitations caused by emotional problems : & \\
\hline - Incompletly accomplished work & 60 \\
\hline - Limited types of activities & 46 \\
\hline Pain interference with normal work & 48 \\
\hline Well-being : & \\
\hline - Feeling calm and peaceful & 62 \\
\hline - A lot of energy & 62 \\
\hline - Feeling down-hearted and blue & 57 \\
\hline Physical health or emotional problems interference with social activities & 67 \\
\hline Kidney disease & \\
\hline Kidney disease interference with patient's life & 41 \\
\hline Time spent by the patient to deal with kidney disease & 37 \\
\hline Frustration caused by kidney disease & 56 \\
\hline Feeling as a burden on patient's family & 78 \\
\hline Symptoms and problems & \\
\hline Sorness in muscles & 35 \\
\hline Chest pain & 33 \\
\hline Cramps & 36 \\
\hline Itchy skin & 32 \\
\hline Dry skin & 61 \\
\hline Dyspnea & 28 \\
\hline Faintness or dizziness & 30 \\
\hline Luck of appetite & 59 \\
\hline Tiredness & 41 \\
\hline Numbness in hands or feet & 41 \\
\hline Nausea & 38 \\
\hline Problems with vascular access & 67 \\
\hline Kidney disease consequences on daily life & \\
\hline Fluid restriction & 65 \\
\hline Dietary restriction & 83 \\
\hline Ability to work around the house & 47 \\
\hline Dependency on doctors and other medical staff & 46 \\
\hline Stress or worries caused by kidney disease & 62 \\
\hline Sex life & 66 \\
\hline Personal appearance & 71 \\
\hline & 63 \\
\hline
\end{tabular}

\section{DisCUSSION \& CONCLUSION}

Little data is available concerning the quality of life (QOL) of Moroccan hemodialysis patients.

In this study, we measured the HRQOL of dialysis patients using the KDQOL-SF 36 tool. Compared to QOL results from other studies, our patients showed similar PCS, MCS and effects of kidney disease scores.

About $38 \%$ of hemodialysis patients in our study had both PCS and MCS scores lower than the critical scores, as established by Lowie et al [8] who showed that a PCS score < 43 and a MCS score < 51 were significantly associated with increased risk of death and hospitalization. In the other domains, we noted lower scores in symptom/problem list and higher scores in burden of kidney disease compared to other studies [9-11].

In our study, MCS scores of our patients were higher than PCS scores similarly to several other studies $[12,13]$. This can be explained by dynamic adaptation of patients' expectations to their chronic illness $[14,15]$.

Early studies indicated that advanced age has a negative impact on the HRQOL [16-18].

In our study, subjects aged of more than 60 years had worse PCS score but similar MCS scores in comparaison with younger patients. In fact, elderly subjects tend to accept their limitations better than the younger ones [19-21]. 
Some subjects experience an improvement in HRQOL after the initiation of dialysis but it can be dependant on the coexistence of comorbidities, the quality of dialysis and the clinical complications of chronic kidney disease such as anemia $[22,23]$ and nutrition state [24].

In our study, cardiovascular disease negatively impacted symptoms/problems and MCS scores in univariate analysis. PCS score correlated positively with dialysis dose and negatively with a parathormone (PTH) rate than $300 \mathrm{pg} / \mathrm{l}$. Despite that $38 \%$ of our patients had PCS and MCS scores lower than the critical scores associated with higher mortality [8], we reported high score in burden of kidney disease. This can be explained by sociocultural factors characterized by strong patient's family support in Moroccan people. The majority of our patients were living with their families. Therefore, families should be encouraged to actively participate in the health care of the hemodialysis patients [25] in order to enhance compliance to treatment as reported by oliviera's et al., [25] through the number of hemodialysis sessions missed by the patient.

Higher socioeconomic, education and employement levels generally are associated with a greater QOL [26, 27].

In our study, unemployed subjects tended to have lower PCS scores and in multivariate analysis, higher educational level was associated with better physical and functional status.

It is well known that assessing the HRQOL of dialysis patients reflects not only patients' satisfaction, but it is independently correlated with morbidity and mortality of this population [28].

This implies that high treatment satisfaction can improve patients' compliance and control disease more effectively. Therefore, patients with lowest PCS and MCS scores in our study might benefit from rehabilitation programmes in order to reduce their morbidity and mortality risks.

\section{REFERENCES}

1. Loos C, Briancon S, Frimat L, Hanesse B, Kessler M. Effect of end- stage renal disease on the quality of life of older patients. Journal of the American Geriatrics Society. 2003 Feb;51(2):229-33.

2. Testa MA, Simonson DC. Assessment of quality-oflife outcomes. N Engl J Med. 1996; 334:835-840.

3. Callahan MB. Using quality of life measurement to enhance interdisciplinary collaboration. Adv Ren Replace Ther. 2001; 8:148-151.

4. Edgell ET, Coons SJ, Carter WB, Kallich JD, Mapes D, Damush TM, Hays RD. A review of healthrelated quality-of-life measures used in end-stage renal disease. Clinical therapeutics. 1996 Sep 1;18(5):887-938.

5. Salzberg DJ, Konari F. Quality of life and rehabilitation in dialysis patients. In Lerma EV, MR Weir Henrich's fifth edition. Principles and practice of dialysis. 2017;34:517-533. Wolters Kluwer.
6. Bouidida B, Rhou H, Ezaitouni F, Ouzeddoun N, Bayahia R, Elhajji K, Roudiès R, Sekkat FZ, Razine R, Abouqal R, Alghadi A. Translation, Cultural Adaptation and Validation of the Kidney Disease Quality of Life-Short Form 1.3 in an African Country. InTransplantation proceedings 2014 Jun 1 (Vol. 46, No. 5, pp. 1295-1301). Elsevier.

7. Hays RD, Kallich RD, Mapes DL. Development of the kidney disease quality of life (KDQOL) instrument. Qual Life Res. 1994;3:329-338.

8. Lowrie EG, Zhang H, LePain N, Lew N, Lazarus JM. The association of SF-36 quality of life scales with patient mortality. CQI Memorandum, Fresenius Medical Care. 1997.

9. Kim JY, Kim B, Park KS, Choi JY, Seo JJ, Park SH, Kim CD, Kim YL. Health-related quality of life with KDQOL-36 and its association with self-efficacy and treatment satisfaction in Korean dialysis patients. Quality of Life Research. 2013 May;22(4):753-8.

10. Fukuhara S, Lopes AA, Bragg-Gresham JL, Kurokawa K, Mapes DL, Akizawa T, Bommer J, Canaud BJ, Port FK, Held PJ. Health-related quality of life among dialysis patients on three continents: the Dialysis Outcomes and Practice Patterns Study. Kidney international. 2003 Nov 1;64(5):1903-10.

11. Seica A, Segall L, Verzan C, Văduva N, Madincea M, Rusoiu S, Cristea S, Ştefan M, Şerbănescu D, Moroşanu P, Grăjdeanu L. Factors affecting the quality of life of haemodialysis patients from Romania: a multicentric study. Nephrology Dialysis Transplantation. 2009 Feb 1;24(2):626-9.

12. Zuniga SMC, Dapueto PJ, Muller OH, Kirsten LL, Alid AR, Ortiz ML. Health related quality of life among patients on chronic hemodialysis. Revista Medica de Chile. 2009; 137(2):200-207.

13. Parsons TL, Toffelmire EB, King-VanVlack CE. Exercise training during hemodialysis improves dialysis efficacy and physical performance. Archive of Physical Medicine and Rehabilitation. 2006; 87(5):680-687.

14. Singer MA, Hpman WM, MacKenzie TA. Physical functioning and mental health in patients with chronic medical conditions. Quality of Life Research. 1999;8:687-691.

15. Parsons TL, Toffelmire EB, King-VanVlack CE. Exercise training during hemodialysis improves dialysis efficacy and physical performance. Archive of Physical Medicine and Rehabilitation. 2006;87(5):680-687.

16. Evans RW, Manninen DL, Garrison Jr LP, Hart LG, Blagg CR, Gutman RA, Hull AR, Lowrie EG. The quality of life of patients with end-stage renal disease. New England journal of medicine. 1985 Feb 28;312(9):553-9.

17. Merkus MP, Jager KJ, Dekker FW, Boeschoten EW, Stevens P, Krediet RT, Necosad Study Group. Quality of life in patients on chronic dialysis: selfassessment 3 months after the start of treatment. American journal of kidney diseases. $1997 \mathrm{Apr}$ 1;29(4):584-92.

18. Baiardi F, Degli Esposti E, Cocchi R, Fabbri A, Sturani A, Valpiani G, Fusarol M. Effects of clinical and individual variables on quality of life in chronic 
renal failure patients. Journal of Nephrology. 2002 Jan 1;15(1):61-7.

19. Ifudu O, Paul HR, Homel $P$, Friedman EA. Predictive value of functional status for mortality in patients on maintenance hemodialysis. American journal of nephrology. 1998;18(2):109-16.

20. Lamping DL, Constantinovici N, Roderick P, Normand C, Henderson L, Harris S, Brown E, Gruen $\mathrm{R}$, Victor C. Clinical outcomes, quality of life, and costs in the North Thames Dialysis Study of elderly people on dialysis: a prospective cohort study. The Lancet. 2000 Nov 4;356(9241):1543-50.

21. Kutner NG, Jassal SV. Quality of life and rehabilitation of elderly dialysis patients. Semin Dial. 2002;15:107-112.

22. Evans RW. Recombinant human erythropoietin and the quality of life of end-stage renal disease patients: a comparative analysis. Am J Kidney Dis. 1991;18(4 Suppl 1):62-70.

23. Mayer G, Thum J, Cada EM, Stummvoll HK, Graf H. Working capacity is increased following recombinant human erythropoietin treatment. Kidney international. 1988 Oct 1;34(4):525-8.
24. Ohri-Vachaspati P, Sehgal AR. Quality of life implications of inadequate protein nutrition among hemodialysis patients. J Ren Nutr. 1999; 9:9-13.

25. Oliveira AP, Schmidt DB, Amatneeks TM, Santos JC, Cavallet LH, Michel RB. Quality of life in hemodialysis patients and the relationship with mortality, hospitalizations and poor treatment adherence. Brazilian Journal of Nephrology. 2016 Dec;38(4):411-20.

26. Moreno F, Gomez JL, Sanz-Guajardo D, Jofre R, Valderrabano F, Spanish Cooperative Renal Patients Quality of Life Study Group4. Quality of life in dialysis patients. A Spanish multicentre study. Nephrology Dialysis Transplantation. 1996 Jan $1 ; 11$ (supp2):125-9.

27. Kutner NG, Devins GM. A comparaison of the quality of life reported by elderly whites and elderly blacks on dialysis. Geriatr Nephrol Urol. 1998;8:7783.

28. Mingardi G, DIA-QOL Group. Quality of life and end-stage renal disease therapeutic programs. Dialysis quality of life. Int J Artif Organs. 1998;21:741-747. 